\title{
Researches on the Transmission of Brand Construction in Hubei University
}

\author{
Deng Yu-hua \\ Hubei University, Hubei Province, China
}

\begin{abstract}
Modern society colleges and universities brand bulidings are more and more important, the brand reflects the school's quality and characteristics, also the realm and the target that school pursued. University competition is largely the brand competition, therefore, the importance of university brand building is self-evident. In the context that the whole society concerned about the brand building, this paper takes Hubei University as an example to clarify the current situation and characteristics of its brand building's communication, analyzing its shortcomings and putting forward the corresponding improvement suggestions, hoping to be helpful to build the brand of Hubei University.
\end{abstract}

Keywords: university brand building, Hubei University, communication research

\section{Introduction}

In the beginning, brand is an economic term, the narrow sense of it refers to the commercial brand, that is to say, it's a way that the enterprise to their products and services identified by the other competitors from the name, terminology, sign, symbol or design and those combination. It is derived from the product And services, but beyond the products and services themselves (XU, 2006, p. 76). However, the university's brand is different from the commercial brand, generally think that the school brand refers to something that gradually accumulated in the creation and development process of school, with a certain degree of visibility and praise include in the comprehensive connotation of the school, condensed in the school's name, logo and teaching facilities, Teachers, campus culture and other elements, it is the concentrated expression of school's philosophy, educational quality, educational characteristics, operating mechanism and the school culture (ZHENG, 2011, p. 72).

Both the Hubei Provincial People's Government and the Ministry of Education build the Hubei University, it is "provincial key comprehensive university", the leader of Hubei Province "2011 plan", selected "the central and western universities based capacity building project". At the same time, Ministry of Education and the British Embassy Approved the establishment of the only IELTS test center in Hubei Province. The university motto "Thinking to make progress, brave efforts to action" reflects the Hubei University has consistently adhered to the educational goals and personnel training requirements. Since its inception in 1931, it transported a large number of talents to the motherland. Over the years, Hubei University has practiced its own brand building and achieved certain achievements. This paper analyzes the status and characteristics of its brand building communication, pointing out its existing problems and putting forward the corresponding improvement proposals.

Deng Yu-hua, Master Student, School of Journalism and Communication, Hubei University. 


\section{The Profile of Hubei University's Brand Building Communication}

\section{Analysis of the Main Body of Communication}

The main body of the transmission of Hubei University's brand building, including Hubei University WeChat, Microblogging, newspapers and websites of this type of official communication, which is the key form of it's brand building; It also includes personal communication between teachers, students and their staff of Hubei University. On the one hand, the official spread based on official consciousness, it has a clear and positive attitude. Assuredly, the official responsible for their remarks and regular updates. On the other hand, personal communication has a strong random and personalized whether published time or published content. In addition, media reports, the government's propaganda and so on also have an important role in the construction of Hubei University's brand, but this paper is the study about the autonomy of Hubei University's brand building, so do not elaborate on this part.

\section{Media Analysis}

Hubei University currently has the official microblogging "Hubei University”, fans concerned about more than 40,000, microblogging released more than 10,000 total; with WeChat Enterprise No. "Hubei University micro portal”, including campus information, Self-help welcome, fault repair, lost property and other 14 forums; There are Hubei University, Shahu spread, Journal of Hubei University and other publications. As well as Hubei University official website, covering the school profile, organization, disciplines, scientific research, personnel training, enrollment and employment, campus culture, public services and other aspects; with radio and television media broadcast platform. From this we can see, Hubei University's brand building has a variety of promotional media, fusing text, picture, video, audio variety media in a whole, establishing an effective publicity platform.

\section{Analysis of the Content of Dissemination}

In order to build its provincial key university brand image, Hubei University spreads information that can build its image through WeChat, microblogging, websites, publications and other forms of communication. The information content is rich, in general can be summarized as academic Meetings, leadership activities, educational reform, student activities, international exchanges, national politics, and people's lives. The academic conference and student activities are the focus of communication because that students and teachers are the most important part of the campus and possessing up the vast majority of the proportion. On the one hand, they need to get the information of campus, on the other hand, the information is also the focus of attention outside the school, such as high school students who want to go to college and educational institutions.

\section{The Analysis of the Effect of Spread}

The so-called effect is to see the extent of its brand building that Hubei University may achieve, from the above content of the spread of view, on the whole, Hubei University disseminate its own brand from various aspects. That is comprehensive and focused, and will be able to reflect all aspects of its university brand, including hardware (teaching equipment, accommodation facilities, etc.) and software (school philosophy, teachers, campus culture, etc.) are presentedfully, the "provincial key comprehensive university" image is merged into the daily communication activities, the propaganda appeal is reflected. Therefore, to a certain extent, Hubei University's brand building communication is more successful. 


\section{Analysis of the Audience of Dissemination}

The audience of Hubei University's brand building communication is the majority of the community, mainly for the country to meet the requirements of the recruitment of school-age graduates and the majority of teachers and students in school. In short, due to the publicity of its propaganda, as long as someone is willing to get information about the Hubei University, he or she can become the audience of its brand building communication. Therefore, For Hubei University's brand building, there are still many hidden audiences, if positive measures and increased publicity efforts are taken to really attract this part of the audience, Hubei University's brand building will be greatly improved.

\section{Characteristics of the Transmission in Hubei University’s Brand Building}

\section{Pay Attention to Academic Exchanges}

Hubei University has a profound cultural heritage, a long history also precipitated a strong academic atmosphere, since the beginning of the school to uphold the school motto of "Thinking to make progress, brave efforts to action", "tirelessly study every day, diligent thinking and will be able to master, broad and profound; determined to ambition, consistent to pursue, and then practical practice, will be able to achieve the ideal purpose”. This is a true portrayal of teachers and students in Hubei University. Hubei University, focusing on students' academic exchanges, emancipating the mind, innovating and embracing, inviting scholars that insight in the academic circles to teach students, regularly hold academic forums, encouraging teachers and students to actively create papers and activate academic atmosphere to lay a deep theoretical foundation.

\section{Reflecting the Humanistic Care}

In the process of brand building, Hubei University uphold the "teaching and educating people" "people-oriented" teaching philosophy, fully embodying the strong humanistic care. Hubei University in the practice of promoting their own image, but also always advocate the rights of teachers and students, for example, when the 85th Anniversary of Hubei University celebration, giving the school more than 20,000 teachers and students free lunch, the school also made special production of halal meal coupons and windows for more than 260 Muslim students to provide "meal”. In addition, reducing tuition fees for the poor students, setting scholarships, free to provide campus network and library's free hot water are the school's long practice, which are reflected from the subtleties of Hubei University of human care, which have an important role for the Hubei University's brand reputation and brand building.

\section{To Strengthen Cooperation With the Media}

Hubei University strengthen cooperation with the media to expand propaganda. Schools can be through news reports, public sponsorship, graduate promotion and school-enterprise associations, etc. to expand exchanges and contacts with society. By widely publicize their own cultural and sports activities, academic research, alumni deeds, school results to the community, the university is able to improve the visibility of the brand and establish a good public image. The university provide news and information for the media, the media promote such a way to cooperate with the media for the school is very effective way to promote the brand image of Hubei University. For example, after the news that "a graduate girl found cancer, teachers and students of Hubei University offer love” published in the Yangtze RiverJournal, it has aroused people’s praise.

\section{The Existing Problems and Suggestions for Improvement}

Although the Hubei University has achieved the "provincial key comprehensive university" goal and 
realized certain results in the process of brand building, but inevitably there are some problems, if some reasonable solution can be obtained, Hubei University's brand image construction will be more success.

Serious dissemination of content homogeneity. In view of the above phenomenon that we can observed, in the spread of Hubei University's brand building, there is a serious problem of content homogeneity. Sometimes, the same event is released in the WeChat, microblogging, campus site through only changing the start or ending, just spread for spreading. So that, resulting in the accumulation of useless information, it is a waste of the reader's times and traffics, leading to the reader's resentment, which is no beneficial to the construction of university brand. The author suggests that schools should take full use of promotional resources, through a variety of platforms, catching innovation and expansion, to release novelty content to avoid the same text and increase the total amount of information.

The Image Is not Prominent Enough. Hubei Province is known as the educational province, Wuhan is the college town, many of which like Huazhong University of Science and Technology, Wuhan University are known for their education strength of the country's top universities. Although Hubei University is the focus of comprehensive University that named after the province of Hubei Province, but consider in the national popularity and the characteristics of image, the two are better. If Hubei University wants to stand out, it must form its own image characteristics, strengthening propaganda to improve the visibility. For example, the Wuhan Institute of Biotechnology provide high standard dormitories to the new students and popular in network, this school caught the point that students really care about the conditions of accommodation, which formed a major feature of the school's brand image, this kind of construction is undoubtedly successful .

The Cooperation With Foreign Media Is not Enough. Most of the media are limited in the province, such as Chutian Metropolis Daily, Wuhan Evening News, Yangtze Daily and so on, in the medias that belong to other provinces, their coverage of Hubei University is very few, this fully shows that Hubei University pay more attention to the publicity that in self province, of course, this has a certain relationship with its "provincial” attribute, but this also has its limitations. The lack of brand building outside the province, leading to the visibility of Hubei University in other provinces are not as significant as it in hubei province. This is no conducive to the establishment of the brand image of Hubei University in the national graduates enrollment and other work will be lost part of the students. It is suggested that Hubei University should increase the academic exchange activities between the other provinces, expanding cooperation with other provinces' media to expand the national influence, the visibility and the brand image construction.

The Campus Tourism Brand Is Missing. Compared with other colleges and universities in Hubei Province, Hubei University's tourism brand is relatively missing. In recent years, with the rise of college campus tour, a large number of tourists into the campus, they not only experienced the campus profound cultural atmosphere, beautiful environment, relaxed mood, but also improved the visibility of colleges, that bring an additional funds to the colleges to better develop themselves. For example, Wuhan University's campus architecture is the fifth batch of key protection of cultural relics, March cherry is more and more becoming the tourism scenery; China Geological University's Yifu Museum is 4A level scenic tourist area; Zhongnan University of Economics and Law Museum is the most complete museum of collection of Chinese currency in China universities. These tourism resources formed a unique side of the brand with its own value (WU, Y. J. LIU, Y. LIU, ZHANG, \& LIU, 2011, p. 122). It is suggested that Hubei University should perfect the overall environmental planning of the campus, building a beautiful campus landscape, repairing the 
potholes pavement and appropriate construction, creating the tourism brand by forming a joint travel with surrounding areas.

\section{Summary}

In this highly developed information age, college competition is very intensified, the construction of brand image is becoming a trump card that all colleges be able to use it to enhance the competitiveness. If the major colleges and universities want to occupy a place, they must give full attentions and researches to construction of brand image. For Hubei University, the results of it achieved in the process is worthy of recognition, but the construction of brand image will be a long way to go, only to form it's own unique characteristics, establish a good image, supplemented by active and effective communication can it play a good colleges compete for this battle and win.

\section{References}

GAO, H. R., \& WANG, L. N. (2010). Talk about brand building in colleges and universities. China Adult Education, 2, 13-14. HAN, Y. (2015). On the internationalization of university brand communication. News and Writing, 8, 102-103.

SHEN, P. Y. (2012). The influence mechanism of university brand image on brand satisfaction and brand loyalty. Journal of East China Jiaotong University, 1, 95-101.

WU, B. B., LIU, Y. J., LIU, Y., ZHANG, J. Q., \& LIU, Z. (2011). Dialogue between city and university-The spread of university and city tourism image. Advertising (Comprehensive Edition), 12, 112-133.

XIAO, R. Y., \& SHI, C. L. (2016). Discussion on the construction and communication strategy of campus media brand in the new media age. Journal of News Research, 15, 26-30.

XU, G. M. (2006). The connotation and prescriptions of university's brand idea. China Higher Education Research, 12 , 76-77.

Zheng, L. (2011). Talking about the brand construction of local colleges and universities. Contemporary Education Forum (Comprehensive Study), 6, 72-74. 